\title{
VISUALIZAÇÃo SINTÉTICO-IMAGÉTICA DE PARÂMETROS E METADADOS DE OBJETOS DE APRENDIZAGEM
}

\begin{tabular}{c}
\hline PREVIEW OF SYNTHETIC IMAGES OF LEARNING \\
OBJECTS METADATA AND PARAMETERS \\
\hline VISTA PREVIA DE IMAGENES SINTÉTICAS DE PARÁMETROS \\
Y METADATA DE OBJETOS DE APRENDIZAJE \\
\hline
\end{tabular}

\author{
Raquel Salcedo Gomes ${ }^{1}$ \\ Daniel Steinbruch Pereira ${ }^{2}$ \\ Érico Marcelo Hoff do Amaral ${ }^{3}$ \\ Rodrigo Sychocki da Silva ${ }^{4}$ \\ Rosana Wagner ${ }^{5}$ \\ Thaísa Jacintho Müller ${ }^{6}$
}

\begin{abstract}
RESUMO
O presente trabalho traz os resultados de pesquisa que objetivou o desenvolvimento de uma linguagem visual que representasse parâmetros e metadados de objetos de aprendizagem de maneira sintético-imagética, a fim de facilitar seu processo de avaliação e seleção por educadores. A pesquisa fundamentou-se em princípios da teoria de NURBS e da lógica do banco de dados de Manovich (2001, 2010), além dos conceitos de objeto de aprendizagem (OA), metadados e sistemas de recomendação. A pesquisa revelou profícua a possibilidade da transformação da cultura subjetiva em dados, mediante a proposição de categorizações que levaram em conta variáveis qualitativas na análise de OAs a partir de teorias de aprendizagem aplicadas ao design instrucional e de características padronizadas utilizadas em sua organização e catalogação em repositórios digitais.
\end{abstract}

PALAVRAS-CHAVE: Visualização-sintético imagética. Objetos de aprendizagem. Metadados. Repositórios. Parâmetros de aprendizagem.

\begin{abstract}
This paper presents results of research aimed at developing a visual language to represent parameters and metadata for learning objects in a synthetic-imagetic manner, in order to facilitate the process of their evaluation and selection by educators. The research was based on principles of NURBS theory and database logic by Manovich (2001, 2010), and the concepts of learning object (LO), metadata and recommendation systems. The inquiry revealed a possibility of fruitful transformation of subjective culture on data through the proposition of categorizations that take into account qualitative variables in the analysis of LOs from the perspective of
\end{abstract}

\footnotetext{
${ }^{1}$ Doutoranda do Programa de Pós-Graduação em Informática na Educação da Universidade Federal do Rio Grande do Sul, doutoranda em em Linguística Aplicada pela Universidade do Vale do Rio dos Sinos. E-mail: salcedogomes@gmail.com

${ }^{2}$ Doutorando do programa de Pós Graduação em Informática na Educação pela Universidade Federal do Rio Grande do Sul. E-mail: danielsteinbruch@gmail.com

${ }^{3}$ Doutorando no Programa de Pós Graduação em Informática na Educação na Universidade Federal do Rio Grande do Sul. E-mail: ericohoffamaral@ gmail.com

${ }^{4}$ Doutorando no Programa de Pós Graduação em Informática na Educação na Universidade Federal do Rio Grande do Sul. E-mail: rodrigo.silva@ caxias.ifrs.edu.br

5 Doutoranda em Informática na Educação pela Universidade Federal do Rio Grande do Sul. E-mail: rosanawagner@gmail.com

${ }^{6}$ Professora da Pontifícia Universidade Católica do Rio Grande do Sul. E-mail: thaisamuller@gmail.com

Recebido em: 11/03/2015 - Aceito em: 09/09/2015
} 
learning theories applied to instructional design and standardized features used in their organization and cataloging in digital repositories.

KEYWORDS: Synthetic-imagetic visualization. Learning objects. Metadata. Repositories. Learning parameters.

\section{RESUMEN}

Este trabajo presenta los resultados de investigación que apuntaba a desarrollar un lenguaje visual para representar parámetros y metadatos de objetos de aprendizaje vía imágenes sintéticas para facilitar su proceso de evaluación y selección de los profesores. La investigación se basa en los principios de la teoría de NURBS y la lógica de la base de datos de Manovich $(2001,2010)$, además de los conceptos de objeto de aprendizaje (OA), metadatos y sistemas de recomendación. La encuesta reveló fructífera la posibilidad de transformación de la cultura subjetiva en datos a través de la proposición de categorizaciones que tuvieron en cuenta las variables cualitativas en el análisis de OA a partir de las teorías de aprendizaje aplicadas al diseño instruccional y características estándar utilizadas en su organización y catalogación en repositorios digitales.

PALABRAS CLAVE: Vista previa de imágenes sintéticas. Objetos de Aprendizaje. Metadatos. Repositorios. Parámetros de Aprendizaje.

\section{INTRODUÇÃO}

Atualmente, há diversos objetos de aprendizagem (OAs) produzidos e disponibilizados em repositórios virtuais (RIVED7, UNESP8, BIOE9), de modo que o professor, ao adotar em seu planejamento pedagógico o uso destes objetos, dispõe de um conjunto de diferentes tipos de OAs construídos a fim de auxiliar na compreensão e elaboração dos conceitos envolvidos em determinada área do conhecimento.

A equipe que produz e disponibiliza OAs muitas vezes não possui relação com o professor que vai utilizá-lo em sala de aula. Portanto, cabe ao docente estabelecer os critérios que determinarão a escolha de um ou mais deles em seu planejamento pedagógico. $\mathrm{O}$ objetivo do presente artigo é apresentar uma alternativa a esse processo, na qual propomos a criação de uma identidade visual para objetos de aprendizagem, construída através da exploração de seus metadados e de parâmetros advindos de teorias de aprendizagem diversas (AUSUBEL, 1968; KOLB, 1986; MAYER, 2001; SWELLER, 2003).

Nossa hipótese reside, portanto, no desenvolvimento de um sistema de recomendação baseado na catalogação sintético-imagética de objetos digitais de aprendizagem, caracterizando-os segundo uma identidade visual. A inspiração para tal proposição advém da teoria de NURBS de Manovich (2010), na qual o autor sugere transformar cultura em dados mediante o uso de imagens na identificação de objetos, a fim de revelar diferentes aspectos que possibilitam ao sujeito questionar uma organização apresentada unicamente em categorias discretas.

A organização textual do artigo segue as seguintes etapas: na segunda seção, há exploração de conceitos referentes a objetos de aprendizagem (OAs), com destaque para os principais conceitos adotados na pesquisa; na terceira seção é apresentada a teoria de NURBS

\footnotetext{
${ }^{7}$ Disponível em: http://rived.mec.gov.br/site_objeto_lis.php.

${ }^{8}$ Disponível em: http://www.acervodigital.unesp.br/handle/123456789/1.

${ }^{9}$ Disponível em: http://objetoseducacionais2.mec.gov.br/.
} 
e aspectos da cultura digital a ela subjacentes como fundamentação teórico-epistemológica da investigação. A seguir, são apresentados os procedimentos metodológicos utilizados para o desenvolvimento do produto resultante da proposta de identidade visual para OAs. Por fim, os resultados são discutidos, bem como possibilidades e percalços da investigação.

\section{OBJETOS DE APRENDIZAGEM: DEFINIÇÃO E PARÂMETROS}

Objetos de aprendizagem vêm sendo aplicados em diferentes áreas do conhecimento, possibilitando práticas pedagógicas alternativas. Eles permitem que conteúdos sejam abordados na forma de imagens digitais, vídeos, hiperdocumentos, animações, simulações, páginas web, jogos educacionais, entre outros (BEHAR, 2009), configurando um processo instrucional multimodal. Também, dos OAs podem emergir outras maneiras de pensar o uso da comunicação, da ciência da informação, da construção do conhecimento e de sua interação com o universo físico e o digital.

\subsection{Objetos de Aprendizagem}

Os OAs surgiram a fim de situar conteúdos educacionais na web para serem reutilizados em diferentes cursos e plataformas, possibilitando a redução de custos da produção de materiais didáticos. Ao longo do tempo, esta ideia inicial foi sendo aprimorada a partir de estudos de diversos pesquisadores, gerando variadas definições para o termo, que apresentam convergências e divergências. Haughey e Muirhead (2005), apontam que existem definições para o termo que se concentram em sua parte "objeto", enquanto outras têm enfatizado o aspecto da "aprendizagem", conforme apresentamos nos parágrafos a seguir.

Segundo Meyer (2008), OA é qualquer recurso digital utilizado nos processos de ensino e aprendizagem suportado por TICs (Tecnologias de Informação e Comunicação). De acordo com o IEEE (2000), um OA é definido como qualquer entidade, que pode ser utilizada, reutilizada ou referenciada durante o aprendizado apoiado por computador. Ele pode conter elementos simples como um texto ou vídeo, ou ainda, um hipertexto, um curso, uma animação com áudio e recursos mais complexos. Wiley (2000) entende que os OAs devem ter as seguintes características: serem auto-explicativos, modulares, agregáveis, digitais, interoperáveis e reutilizáveis. Ressaltamos que os OAs têm pouca utilidade fora dos contextos educacionais, seu valor está em sua aplicação às configurações de sala de aula e ambientes online nos quais os professores podem ou não estar presentes (HAUGHEY; MUIRHEAD, 2005).

\subsection{Metadados}

Para facilitar a adoção dos OAs, o Learning Technology Standards Committee (LTSC) do IEEE, em 1996, forneceu padrões instrutivos da tecnologia (LTSC, 2000). Segundo a IEEE/LTSC (2000), o padrão LOM (Learning Object Metadado) focaliza o conjunto mínimo de atributos necessários para permitir que um OA seja gerenciado, localizado e avaliado. 
Os metadados permitem a catalogação e a codificação do OA, tornando-o compreensível para as diversas plataformas. Considerando-se que a principal característica de um OA é sua reusabilidade, posta em prática através de repositórios em que são armazenados, é importante que possam ser localizados a partir da busca por temas, por nível de dificuldade, por autor ou por relação com outros objetos. Para que um OA possa ser recuperado e reutilizado, é preciso que seja devidamente indexado e armazenado em um repositório.

\subsection{Sistemas de recomendação}

Com a quantidade de informações disponibilizada pelo acesso à internet, as pessoas deparam-se com ampla diversidade de opções. Muitas vezes, um indivíduo possui pouca experiência no processo de escolha entre as várias alternativas de conteúdos que lhe são apresentadas (CAZELLA et al., 2011).

Os sistemas de recomendação auxiliam no aumento da capacidade e eficácia do processo de indicação (CAZELLA et al., 2009). Em um sistema típico de filtragem de informação, as pessoas fornecem recomendações como entradas e o sistema as agrega e direciona aos indivíduos considerados potenciais interessados neste tipo de recomendação. Um dos grandes desafios desses sistemas é realizar a combinação adequada entre as expectativas e perfis dos usuários e os produtos, serviços e pessoas a eles recomendados, ou seja, definir e descobrir este relacionamento de interesses. Pode-se, por exemplo, vislumbrar um aluno sendo exposto a uma grande quantidade de OAs que procuram auxiliá-lo em sua formação. Os sistemas de recomendação, neste caso, funcionam como filtros de informação encaminhando o objeto de aprendizagem que melhor atende o aluno no que concerne a suas necessidades contingenciais de aprendizado (CAZELLA et al., 2011). Com base nestas premissas é que pretendemos realizar a identificação visual de objetos de aprendizagem, para que, através dela, um sistema de recomendação baseado em sua catalogação sintéticoimagética possa ser criado.

\section{IMAGEM-SÍNTESE COMO FORMA SIMBÓLICA}

Assim como os demais objetos digitais, além de hospedados em endereços eletrônicos próprios, os OAs são costumeiramente armazenados em repositórios digitais ou bancos de dados na internet (SILVA et al., 2010, p. 96). Manovich (2001) afirma que a lógica do banco de dados é a forma simbólica predominante na contemporaneidade, substituindo a narrativa, que imperou na primeira modernidade como organizadora da cultura e meio de compreensão da sociedade:

De fato, se após a morte de Deus (Nietzche), do fim das grandes Narrativas do Iluminismo (Lyotard) e com a chegada da Web (Tim Berners-Lee), o mundo aparece-nos como uma coleção sem fim e não estruturada de imagens, textos, e outros registros de dados, é bastante apropriado que sejamos movidos a modelá-lo como um banco de dados. Mas é também conveniente que queiramos desenvolver uma poética, uma estética e uma ética deste banco de dados (MANOVICH, 2001, p. 195, tradução nossa). 
Para o autor, na ciência da computação, o banco de dados é definido como uma coleção estruturada de dados. Os dados armazenados em um banco são organizados para pesquisa rápida e recuperação automática e, portanto, são tudo menos uma simples coleção de itens. Diferentes tipos de bancos de dados - em rede, hierárquicos, relacionais e orientados a objetos - usam diferentes modelos para organizar seus dados. Por exemplo, os registros em bancos de dados hierárquicos são organizados em uma estrutura arbórea. Bancos de dados orientados a objetos armazenam estruturas complexas de dados, chamadas "objetos", que são organizadas em classes hierárquicas que podem herdar propriedades de classes mais altas da cadeia (MANOVICH, 2001, p. 194). Cientistas da informação, como Weinberger (2007) e Silva et al. (2010) reiteram a demanda por filtros organizacionais, que otimizem o acesso a objetos digitais, mediante seleção, arquivamento e organização prévia desempenhadas por especialistas.

Weinberger (2007, p. 32) destaca que, no espaço quase ilimitado da internet, sem barreiras físicas, os itens podem ser dispostos e armazenados em qualquer ordem e sequência, de acordo com a demanda de cada usuário. Não há necessidade de compilação espacial, seguindo ordens numéricas ou a ordem alfabética. Os critérios de organização e seleção dos itens podem ser aqueles buscados pelo usuário, de modo que, quanto mais parâmetros de organização e busca tiverem, mais chance terão os objetos de serem encontrados.

Se, no mundo físico, a catalogação limitava-se a uma lista de poucas palavras-chaves e um pequeno número de categorias discretas, na era digital as categorias e parâmetros de armazenamento podem ser maiores do que o objeto em si, isto é, quanto mais tags (etiquetas) um objeto digital tiver atrelado a si, mais chances terá de ser encontrado, visualizado e utilizado. A este respeito, Manovich (2010, p. 198) usa a metáfora do mapa, afirmando que este, na era digital, "tornou-se maior do que o território".

Os metadados que acompanham os OAs funcionam como essas etiquetas que permitem sua identificação mais acurada. Acompanhado de metadados, cada OA recebe informações descritivas que permitem que sejam facilmente encontrados por intermédio de um sistema de busca (SILVA et al., 2010, p. 95). Tais metadados estão intimamente imbricados às características de acessibilidade, reusabilidade, interoperabilidade, portabilidade e durabilidade pressupostas a OAs de acordo com Wiley (2000).

O uso de metadados para descrição dos OAs pode constituir um processo profícuo para sua documentação, pois provê uma organização ao repositório, permite a busca e a localização customizada por parte dos usuários, sendo especialmente útil quando os recursos não são textuais e não podem ser indexados por sistemas automáticos como, por exemplo, recursos multimídias ou em áudio.

Tendo em vista o processamento de metadados transformados em imagens sintéticas, Manovich (2010) desenvolveu seus software studies, com ênfase na teoria de NURBS (Non Uniform Rational Basis Spline) ou Linha de Base Racional Não Uniforme, uma técnica da computação gráfica para representar superfícies. Manovich (2010) acredita ser este um novo 
modo de visualização gráfica e interativa de informações. Seu método de análise considera a possibilidade da cultura equiparada a seus objetos. Seu uso é capaz de revelar as mudanças graduais na sensibilidade ou na imaginação ao longo da história, colocando em cheque o arquivamento apenas através de categorias discretas, atribuindo-lhe certa classificação qualitativa.

O autor acredita na emergência das ideias de fluxo, evolução, complexidade, heterogeneidade, hibridização cultural e interação, de modo a revelar contornos inéditos para a problematização da tecnologia no contexto específico da cultura. Para ele, formatos devem ser coerentes com o caráter transitório e momentâneo dos objetos digitais, tendendo à revalidação de paradigmas científicos na experimentação artística. $\mathrm{O}$ que tentamos nesta pesquisa é imprimir elementos estéticos à catalogação científica e estruturada de OAs, com inspiração no diálogo entre artes, ciência e tecnologia proposto por Manovich.

Embora afirme que uma história sistemática da exibição dos dados visuais ainda esteja por ser pesquisada e escrita, Manovich (2010) reitera que o uso de representações matematicamente definidas de qualidades contínuas foi largamente acelerado após os anos 1960, devido à adoção de computadores para a criação automática de gráficos. Ele recorda que, quando os campos do design, da mídia e da arquitetura adotaram softwares de computação gráfica, nos anos de 1990, produziu-se uma revolução estético-intelectual, com o aumento na velocidade de processamento dos computadores e de sua capacidade de memória, o que ofereceu condições práticas para a modelagem em NURBS originalmente desenvolvida por Steven Coons nos anos de 1960.

Essa técnica para representar formas espaciais forçou um distanciamento da geometria retangular modernista no campo do pensamento arquitetônico e a preferência por formas suaves e complexas criadas a partir de curvas contínuas. Como resultado, curvas suaves e superfícies com formas livres emergiram como nova linguagem de expressão para o mundo globalizado e ligado em rede, onde a única constante é a mudança. A estética modernista da simplicidade e discrição foi substituída pela estética da continuidade e complexidade.

Manovich (2010) informa que o discurso arquitetônico se tornou dominado por conceitos e termos que igualam elementos do design e das operações oferecidas pelos softwares. Para ele, a computação gráfica não foi a única fonte de inspiração a esse novo conceito, pois influências importantes vieram da filosofia francesa e da ciência do caos e da complexidade. De todo modo, a computação gráfica tornou-se linguagem do design e da arquitetura.

Seguindo os arquitetos que adotaram técnicas de computação gráfica para falar sobre seu campo, Manovich (2010, p. 43) propõe fazer o mesmo com todo o campo cultural, superando o uso desses termos como metáforas e visualizando, empiricamente, processos culturais, suas dinâmicas e fluxos através técnicas de computação gráfica: "design, animação e softwares de visualização permitem conceituar e visualizar fenômenos e processos culturais 
em termos de parâmetros de mudança contínua, em oposição aos padrões categóricos, 'caixas' de hoje".

Assim como o software substituiu o antigo design das primitivas platônicas por novas primitivas (curvas, superfícies flexíveis, campos de partículas), a teoria de NURBS propõe substituir a tradicional "teoria cultural das primitivas". Desse modo, uma linha do tempo 1D se torna um gráfico 2D ou 3D, um pequeno conjunto de campos categóricos discretos é descartado em nome de curvas, superfícies livres em 3D, campos de partículas e outras representações disponíveis nos softwares de design e visualização. A inspiração para seus software studies vem de campos baseados na computação gráfica para visualizar dados visualização científica, visualização da informação e "visualização artística", além de interfaces padrões utilizadas na edição de mídia e em softwares de composição e animação que empregam curvas para visualizar as mudanças em vários parâmetros da animação ao longo do tempo.

A partir de um conjunto de coordenadas $\mathrm{X}$ e Y, faz-se o mapeamento de um processo cultural em um conjunto de números, onde um número pode ser o tempo (eixo X) e o outro alguma qualidade do processo naquele período (eixo $\mathrm{Y}$ ), de modo que a cultura é transformada em dados. Os software studies de Manovich propõem lidar com uma manifestação particular da cultura: os objetos, pois, para o autor, são eles que manifestam mudanças em suas sensibilidades culturais, imaginação ou estilo. Nesse sentido, é que nos foi possível pensar no processamento de metadados de OAs a fim de transformá-los em imagenssíntese.

Segundo Manovich (2010), utilizar números no eixo X (por exemplo, tempo) é fácil, pois normalmente os objetos culturais têm alguns metadados discretos ligados a eles - a data ou lugar de criação, o tamanho, a duração etc. Então, tendo a data em que o objeto foi criado, pode-se inserir esses números como metadados no eixo X. Quanto ao eixo Y, pode ser adquirido mediante a anotação manual de conteúdos, ou uso de outros dados discretos. Visto que é difícil ordenar um grande número de objetos muito similares entre si, há a necessidade de alguns métodos automáticos que podem ser processados em computadores para descrever qualidades de um grande número de objetos culturais qualitativamente, gerando imagens complexas.

Concordantemente a teorizações de Flusser (2007), Santaella e Nöth (2001, 2005) e Manovich (2001), podemos ainda salientar que as formas de comunicação na contemporaneidade passam por um fenômeno de proliferação de imagens, a partir da reprodutibilidade técnica e das Tecnologias de Comunicação e Informação (TICs). Flusser (2007) afirma que a imagem remete a uma leitura sintética, ao passo que a informação verbal, a uma leitura analítica. É necessário seguir o texto se quisermos captar sua mensagem, enquanto a "mensagem" da imagem pode ser apreendida e, somente depois, decomposta. Essa é, então, a diferença entre a linha de uma só dimensão e a superfície de duas dimensões: uma almeja chegar a algum lugar e a outra já está lá, mas pode mostrar como chegou. 
Intenta-se, a partir do processamento em coordenadas $\mathrm{X}$ e $\mathrm{Y}$ de metadados de objetos de aprendizagem, criar imagens que os sintetizem, possibilitando sua visualização abstrata. Tais imagens-síntese poderiam ser inicialmente utilizadas como identidades de apresentação de OAs, ou, posteriormente, prover novos modos de categorização, armazenamento e busca, funcionando como etiquetas visuais de sistemas de recomendação.

\section{GERAÇÃO DE IMAGENS-SÍNTESE DE OAs}

O desenvolvimento desta pesquisa ocorreu em um conjunto de etapas distintas, e cada fase foi marcada por um grupo de ações específicas. A partir da definição do problema de pesquisa: Como gerar imagens-síntese de metadados e parâmetros de aprendizagem em OAs?, que caracterizou a etapa de fundamentação teórico-epistemológica do estudo, partiu-se para o levantamento de um referencial que atendesse ao desenvolvimento de um método para avaliação e sistematização de características de OAs, resultando na demonstração destes objetos sob uma perspectiva imagética.

Buscou-se desenvolver uma solução que permitisse identificar os principais aspectos relacionados aos OAs, observando as diferentes características destes softwares em relação a sua efetividade como instrumentos de auxílio na construção do conhecimento (parâmetros), além de características intrínsecas a eles, já definidas por padrões internacionais (metadados). Portanto, a investigação fez uso de duas fontes distintas para categorização de OAs: variáveis subjetivamente geradas a partir de pressupostos de teorias de aprendizagem, as quais estamos considerando como nossas variáveis da coordenada Y, conforme Manovich (2010), visto que foram selecionadas e atribuídas por nós, e variáveis quantitativas de metadados de OAs, tomados como as variáveis da coordenada $\mathrm{X}$, como dados intrínsecos a OAs já previamente estabelecidos pelo padrão LOM de classificação.

\subsection{Variáveis geradas a partir de teorias de aprendizagem (Eixo Y)}

Para construção do método, a fim de que de atendesse à classificação e mensuração subjetiva dos OAs (eixo Y), optou-se pela observação de alguns pontos pertinentes apresentados na literatura de teorias de aprendizagem aplicadas ao design instrucional, conforme segue:

1. A teoria da carga cognitiva de Sweller (2003), a qual descreve o alinhamento do processo de informação com o processo cognitivo humano como uma das melhores formas de se realizar uma aprendizagem eficiente, ou seja, quando o volume de informações oferecidas ao aluno é compatível com sua capacidade de compreensão.

2. O Ciclo de Aprendizagem Vivencial (CAV) de Kolb (1986), que defende que uma pessoa passa primeiro por uma experiência concreta para depois refletir sobre ela e disso abstrair e internalizar significados. Essa "bagagem" de conhecimentos, valores ou crenças pessoais pode então ser utilizada em outras situações, possivelmente diferentes da primeira. Ao chegar a essa última fase, o ciclo é reiniciado, de modo que 
o processo de concepção da aprendizagem humana seja articulado em quatro etapas consecutivas:

a) Vivências completas: envolvimento do indivíduo;

b) Observações e reflexões: contato com o mundo;

c) Conceitos abstratos: novo contato com a realidade, a partir de novos conhecimentos;

d) Testes: experimentação ativa das novas informações e conceitos.

3. Os princípios de design instrucional propostos por Mayer (2001): representação múltipla, com a integração das diferentes tecnologias e mídias; proximidade espacial, com os enunciados e rótulos próximos das imagens, vídeos e animações; diferenças individuais, permitindo que os alunos de níveis variados possam avançar ou recuar dentro do objeto, de acordo com o seu potencial de aprendizagem e conhecimento; coerência, com a simplificação dos conteúdos disponibilizados, a fim de que o aluno possa se focar nos assuntos pertinentes; e, por último, o princípio da redundância, com a integração de áudio, vídeo e animações no mesmo contexto em momentos diferentes de uma atividade específica.

4. A teoria de Ausubel (1968), que prevê, como requisito a uma aprendizagem significativa, que as novas informações disponibilizadas para um determinado OA relacionem-se com um elemento relevante da estrutura de conhecimento do indivíduo por meio de uma etapa básica de nivelamento, criando condições para que os dados apresentados tenham sentido para o aluno.

A partir destes conceitos, foram elencadas variáveis com o intuito de construir modelos gráficos que ajudaram na geração das características da aplicação, com base nos pressupostos defendidos por estes teóricos da aprendizagem. As imagens resultantes da quantificação dessas diversas variáveis deveriam possuir diferente intensidade de cores, formas e tamanhos, demonstrando visualmente o quanto o software atende aos princípios das teorias de aprendizagem arroladas, aplicadas ao design instrucional. Desta forma, o trabalho desta etapa foi dividido em duas partes:

1. Análise de aspectos pertinentes aos OAs, definição de variáveis e quantificação.

2. Implementação da aplicação para construção de imagem a partir do resultado da primeira parte (variáveis subjetivamente classificadas).

A seguinte estrutura foi elaborada, a partir do referencial teórico estudado:

Teoria da carga cognitiva - Sweller (2008)

Variável:

T (Peso de 1 a 5) - Avaliação da aprendizagem de acordo com o alinhamento do processo de informação - as informações estão de acordo com a capacidade de compreensão do aluno, sendo 1 a pertinência mínima e 5 a máxima.

Ciclo de Aprendizagem Vivencial - Kolb (1986)

Variáveis: 
VC (Peso de 1 a 5) - Aborda as vivências completas, o envolvimento do indivíduo.

OR (Peso de 1 a 5) - Aborda o contato da aplicação com o mundo.

CA (Peso de 1 a 5) - Aborda a apresentação de conceitos abstratos, o novo contato com a realidade a partir da construção do conhecimento.

TS (Peso de 1 a 5) - Aborda a relação de testes, apresentados ou não no OA.

CAV (Peso de 1 a 5) - Peso total, média entre todas as variáveis CAV.

Princípios de Mayer (2001)

Variáveis:

RM (Peso de 1 a 5) - Avalia a integração das diferentes tecnologias e mídias no OA.

PE (Peso de 1 a 5) - Avalia o quanto os enunciados e rótulos estão próximos às imagens, vídeos e animações.

DI (Peso de 1 a 5) - Avalia o quanto o OA permite aos alunos de níveis diferentes avançar ou recuar dentro do objeto, de acordo com seu potencial de aprendizagem e conhecimento.

CO (Peso de 1 a 5) - Avalia o nível de simplificação dos conteúdos disponibilizados.

RD (Peso de 1 a 5) - Avalia o nível de integração entre áudio, vídeo e animações no mesmo contexto em momentos diferentes de uma atividade específica no OA.

PM (Peso de 1 a 5) - Média entre as variáveis apresentadas acima.

Aprendizagem Significativa - Ausubel (1968)

Variável:

AS (Peso de 1 a 5) - Avalia o OA quanto à integração do tema com as áreas de conhecimento, se existe relação com o conhecimento do aluno.

\subsection{Variáveis extraídas de metadados (Eixo X)}

O outro método adotado para complementar a geração de variáveis, desta vez as correspondentes ao eixo X das coordenadas de Manovich (2010), foi a quantificação dos metadados padrão, já pré-definidos a todos os OAs. A tabela 1 demonstra metadados prédefinidos pelo padrão LOM (Learning Object Metadado), que foram sintetizados e representados através de variáveis numéricas, sendo que alguns deles foram considerados não pertinentes por serem irrelevantes à sintetização imagética ou por não estarem disponíveis a partir de seu processo de catalogação.

TABELA 1 - Representação dos metadados em variáveis

\begin{tabular}{|c|c|c|c|}
\hline \multicolumn{2}{|c|}{ Categoria Geral } & \multicolumn{2}{c|}{ Variável } \\
\hline Identificador & & CGI & $\begin{array}{c}\text { valor numérico } \\
\text { inteiro }\end{array}$ \\
\hline Nome/Título & contagem dos caracteres do nome & CGN & $\begin{array}{c}\text { valor numérico } \\
\text { inteiro }\end{array}$ \\
\hline
\end{tabular}




\begin{tabular}{|c|c|c|c|}
\hline Localização & não pertinente & & \\
\hline Palavra-chave & não pertinente & & \\
\hline Idioma & bandeira & CGL & $\begin{array}{l}\text { bandeira do país ou } \\
\text { sigla }\end{array}$ \\
\hline Descrição & não pertinente & & \\
\hline \multicolumn{2}{|r|}{ Categoria Ciclo de Vida } & \multicolumn{2}{|r|}{ Variável } \\
\hline Versão & objeto (pontos) para definir a versão & CVV & $\begin{array}{l}\text { número de pontos } \\
\text { identifica a versão }\end{array}$ \\
\hline $\begin{array}{l}\text { Entidades que } \\
\text { contribuíram }\end{array}$ & número de entidades (instituições) envolvidas & CVE & $\begin{array}{l}\text { valor numérico } \\
\text { inteiro }\end{array}$ \\
\hline Data & apenas o ano & CVD & $\begin{array}{l}\text { valor numérico } \\
\text { inteiro }\end{array}$ \\
\hline Tipo de contribuição & não pertinente & & \\
\hline Status & não pertinente & & \\
\hline \multicolumn{2}{|r|}{ Categoria Técnica } & \multicolumn{2}{|r|}{ Variável } \\
\hline Formato & não pertinente & & \\
\hline Tamanho & tamanho do arquivo em bytes & CTT & $\begin{array}{l}\text { valor numérico } \\
\text { inteiro }\end{array}$ \\
\hline Tipo de Tecnologia & número de tecnologias utilizadas & CTTec & $\begin{array}{l}\text { valor numérico } \\
\text { inteiro }\end{array}$ \\
\hline Nome da tecnologia & não pertinente & & \\
\hline Duração & $\begin{array}{c}\text { faixas de tempo (Likert - de } 1 \text { a } 5 \text { ) 5/10/15/30/60 ou } \\
+\end{array}$ & CTD & Faixa de duração \\
\hline & Categoria Educacional & & Variável \\
\hline Tipo de interatividade & \multirow{3}{*}{ valores observados nas variáveis já definidas } & & $\begin{array}{l}\text { representação ativa, } \\
\text { expositiva ou mista. }\end{array}$ \\
\hline Nível de interatividade & & & medidor de bateria \\
\hline $\begin{array}{l}\text { Recursos de } \\
\text { aprendizagem }\end{array}$ & & & \\
\hline Usuário final esperado & não pertinente & & \\
\hline
\end{tabular}




\begin{tabular}{|c|c|c|c|c|}
\hline Ambiente de utilização & $\begin{array}{c}\text { sistema operacional - identificação numérica para o } \\
\text { número de sistemas em que a aplicação roda }\end{array}$ & CEA & $\begin{array}{c}\text { valor numérico } \\
\text { inteiro }\end{array}$ \\
\hline Descrição & variável que utiliza como base as idades do público- \\
alvo & CEF & $\begin{array}{c}\text { valor numérico } \\
\text { inteiro }\end{array}$ \\
\hline Catária & escala com faixas de valores & CDC & escala de 1 a 5 é sim \\
ou não
\end{tabular}

Fonte: os autores

A partir do padrão LOM, foram analisadas 5 categorias de dois OAs. O primeiro OA constitui-se de uma Apostila de Instrumentalização para o Ensino a Distância, oriunda do repositório CESTA (Coletânea de Entidades de Suporte ao uso de Tecnologia na Aprendizagem) da Universidade Federal do Rio Grande do Sul. Esta apostila visa ensinar docentes a discentes a fazer uso eficiente de ambientes virtuais de aprendizagem. $\mathrm{O}$ segundo, um vídeo, intitulado "Motivação: existe mesmo um modo de ensiná-la aos alunos ?", foi acessado no BIOS (Banco Internacional de Objetos Educacionais). Este OA é voltado a formação continuada de docentes e visa levar o professor a refletir sobre o papel da motivação discente na aprendizagem. Tal escolha foi feita de modo aleatório, os únicos critérios foram a busca por OAs de repositórios e tipo de tecnologia diferentes (apostila X vídeo), por acreditarmos que tais diferenças acentuariam o cotejo das imagens-síntese resultante das análises, a partir de diferenças profundas no eixo $\mathrm{X}$ e, principalmente, no eixo Y.

As categorias utilizadas do padrão LOM foram Geral, Ciclo de Vida, Técnica, Educacional e Direitos. Dentro da categoria Geral, foram avaliadas as três subcategorias CGI, que corresponde à categoria geral "identificador", CGN, que corresponde à categoria geral "nome", e CGL, correspondente à categoria geral "lugar", isto é, o país de origem do OA. Dentro da categoria Ciclo de Vida, foram analisadas as subcategorias CVV, CVE, CVD, em que CVV corresponde ao Ciclo de Vida Versão, CVE corresponde ao Ciclo de Vida Entidade e CVD corresponde ao Ciclo de Vida Data. Na categoria Técnica, foram avaliadas as categorias CTT, CTTEC e CTD, em que CTT refere-se ao tamanho dos objetos em bytes, CTTEC refere-se ao tipo de tecnologia, em que se definiu que 1 equivale a texto bidimensional, 2 a vídeo, 3 a jogo digital, 4 a objeto tridimensional e 5 a software. A categoria CTD refere-se ao tempo de duração de utilização do OA, que foi definido em 5 categorias divididas em minutos, correspondendo a 5, 10, 15, 20, 25 ou mais minutos de uso a fim de concluir a tarefa proposta no OA. 
Dentro da categoria educacional, foram analisadas as categorias CEA e CEF, em que CEA refere-se a Categoria Educacional Ambiente de Utilização, isto é, em quantos sistemas operacionais o OA pode ser acessado, sendo que, se ele pode ser acessado em apenas um sistema, lhe é atribuído valor 1 , dois sistemas, valor 2 e assim, por diante, sendo que, se o OA pode ser acessado por mais de 4 sistemas, atribuísse-lhes o valor 5. Já a categoria CEF equivale à faixa etária para a qual o OA foi desenvolvido, tendo em vista seu público-alvo.

Dentro da categoria Direitos, foram consideradas as categorias CDC e CDDA, em que CDC refere-se ao custo de utilização do OA, ou seja, se seu acesso é pago ou gratuito, e CDDA refere-se aos Direitos Autorais do OA, se possui restrições de Direitos Autorais ou não.

A Tabela 2 apresenta uma síntese de todas as categorias utilizadas na produção de variáveis, tanto aquelas oriundas de análises subjetivas a partir de teorias de aprendizagem, quanto aquelas selecionadas do padrão internacional LOM. A opção por duas fontes distintas de geração de variáveis deu-se em virtude da tentativa de seguir a máxima de Manovich (2010), de transformar cultura em dados a partir da subjetividade dos analistas, fazendo uso de categorias oriundas de pressupostos teóricos e modelos pedagógicos de design instrucional.

TABELA 2 - Síntese das categorias propostas

\begin{tabular}{|c|c|c|c|c|}
\hline \multicolumn{3}{|r|}{ Modelo } & OA1 & OA2 \\
\hline \multicolumn{3}{|c|}{ Teorias Educacionais } & $\begin{array}{c}\text { Apostila de instrumentalização } \\
\text { para o ensino à distância }\end{array}$ & $\begin{array}{c}\text { Motivação: existe mesmo } \\
\text { um modo de ensiná-la } \\
\text { aos alunos? }\end{array}$ \\
\hline \multicolumn{5}{|c|}{ Sweller } \\
\hline$T$ & 1 a 5 & & 2 & 4 \\
\hline \multicolumn{5}{|c|}{ Kolb } \\
\hline VC & 1 a 5 & & 3 & 4 \\
\hline OR & 1 a 5 & & 2 & 5 \\
\hline CA & 1 a 5 & & 3 & 3 \\
\hline TS & 1 a 5 & & 3 & 3 \\
\hline CAV & 1 a 5 & & 3 & 4 \\
\hline \multicolumn{5}{|c|}{ Mayer } \\
\hline RM & 1 a 5 & & 3 & 3 \\
\hline $\mathrm{PE}$ & 1 a 5 & & 3 & 4 \\
\hline
\end{tabular}




\begin{tabular}{|l|l|l|l|l|}
\hline DI & 1 a 5 & 1 & 3 \\
\hline CO & 1 a 5 & 4 & 3 \\
\hline RD & 1 a 5 & 3 & 5 \\
\hline PM & 1 a 5 & 2 & 5 \\
\hline \multicolumn{5}{|c|}{ Ausubel } \\
\hline AS & 1 a 5 & 2 & 3 \\
\hline
\end{tabular}

Metadados

Geral

\begin{tabular}{|l|l|l|l}
\hline CGI & inteiro & identificador & \\
\hline CGN & inteiro & titulo & 49 \\
\hline CGL & bandeira & idioma & \\
\hline
\end{tabular}

Ciclo de Vida

\begin{tabular}{|l|l|l|l|l|}
\hline CVV & pontos & versão -numero de pontos & 1 & 1 \\
\hline CVE & inteiro & no entidades & 1 & 1 \\
\hline CVD & inteiro & data & 2010 & 2011 \\
\hline
\end{tabular}

Técnica

\begin{tabular}{|l|l|l|l|l|}
\hline CTT & inteiro & tamanho & 1780 & 315200 \\
\hline CTTEC & inteiro & tipo tecnologia & 1 & 2 \\
\hline CTD & 1 a 5 & Duração $-5 / 10 / 15 / 30 / 60$ ou +5 & 3 \\
\hline \multicolumn{2}{|c|}{ Educacional }
\end{tabular}

\begin{tabular}{|l|l|l|lr}
\hline CEA & inteiro & ambiente utilização & 5 & \\
\hline CEF & inteiro & faixa etária & & $14-17$ \\
\hline
\end{tabular}

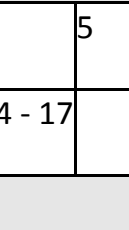

\begin{tabular}{|l|l|l|l|}
\hline CDC & 1 a 5 & custo & 0 \\
\hline CDD & 0 ou 1 & direitos autorais & 0
\end{tabular}

Fonte: os autores

\subsection{Geração das imagens-síntese: sólidos geométricos}


Decidiu-se que a imagem-síntese gerada de cada OA consistiria num sólido geométrico cilíndrico. Para a criação dos sólidos coloridos, foi utilizado o software Winplot, o qual se trata de um programa de geração de gráficos 2D e 3D a partir de funções e equações matemáticas. Como última etapa do projeto, cada três integrantes do grupo de pesquisa analisaram um OA e geraram sua imagem correspondente.

Com base nas informações descritas, partiu-se para a produção estética em si, isto é, para a geração de uma imagem correspondente às características de catalogação no padrão LOM (eixo X) e da adequação às teorias de aprendizagem aplicadas ao design instrucional de cada OA analisado, cujas variáveis já haviam sido descritas e extraídas. Como se pôde observar na Tabela 2, as 13 primeiras variáveis admitem valores apenas entre 1 e 5 . Sendo assim, resolveu-se reduzir as demais variáveis também para esta faixa de valores.

Para isto, foi usada a noção matemática de classe residual (congruência módulo 5), a saber: cada número natural, ao ser dividido por 5, deixa um resto entre 0 e 4 . Resolveu-se, então, dividir os demais números presentes na tabela, fora da faixa considerada, por 5 e considerar apenas o resto da divisão. Caso o resto seja 0 , é considerado como 5 , uma vez que o número 0 e o número 5 fazem parte da mesma classe residual (aquela que deixa resto 0 quando da divisão por 5).

Feita esta classificação, com todas as variáveis na faixa de valores 1 a 5, partiu-se para a definição de curvas de nível, que, juntas, formaram um sólido. Definiu-se que cada uma das linhas da Tabela 2 corresponderia a um disco, cujo tamanho do raio fora determinado exatamente por estes valores obtidos ( 1 a 5 ). A sobreposição destes discos formou um sólido, que representa o OA em questão.

Além disso, separou-se a tabela em "blocos", cada um deles correspondendo a uma cor, ou seja, os discos de cada bloco (cuja separação pode ser vista na Tabela 2 pelas linhas de cor cinza) são de uma mesma cor. A intensidade desta cor foi dada também pelo valor obtido entre 1 e 5 , de modo que, quanto mais alto o número, mais forte a coloração. Para a escolha das cores foi usada a tabela de cores RGB. Desta forma, quanto mais intensa a coloração do sólido, mais ele atende aos princípios considerados em sua avaliação.

Ainda sobre a geração do sólido em si, para representação de cada curva de nível no espaço tridimensional, foram usadas equações paramétricas, dadas por $\mathrm{x}=\mathrm{n} \cdot \cos (\mathrm{t}), \mathrm{y}=$ $\mathrm{n} . \operatorname{sen}(\mathrm{t})$ e $\mathrm{z}=\mathrm{k}$, onde $\mathrm{n}$ representa o raio do disco (no caso, um valor entre 1 e 5 ) e $\mathrm{k}$ sua altura no eixo $z$, dada arbitrariamente com a intenção de que os discos fiquem visualmente sobrepostos. Como o Winplot apresentou-se bastante limitado com relação à mudança de cores, os sólidos gerados foram colados no Paint, onde, manualmente, foram alteradas as cores dos discos, bem como sua intensidade. A definição da cor de cada bloco foi feita conforme a Figura 1.

Definidas as coordenadas e as cores, foram gerados dois sólidos, o primeiro sintetizado visualmente o OA1, Apostila de instrumentalização para o ensino à distância e o 
segundo sintetizando as categorias analisadas para o OA2, o vídeo Motivação: existe mesmo um modo de ensiná-la aos alunos?.

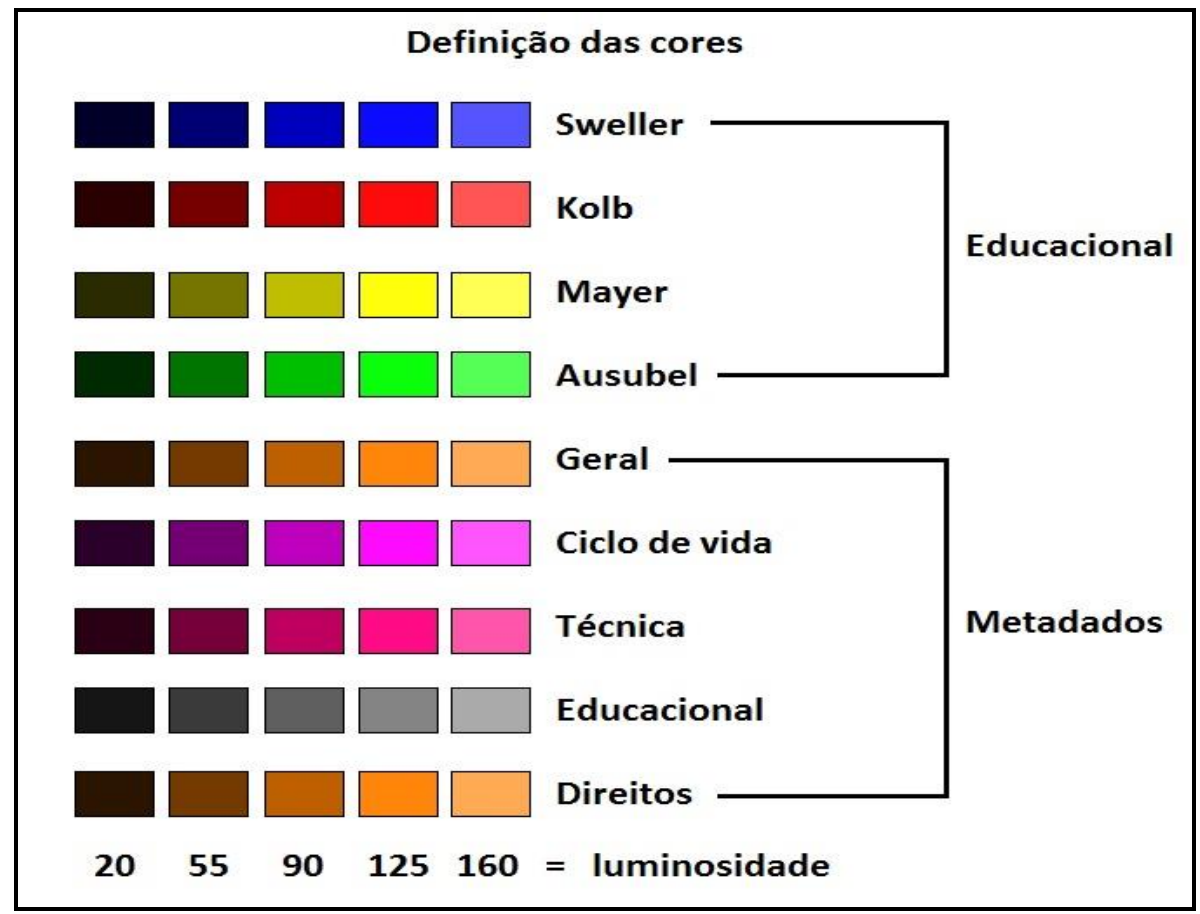

FIGURA 1 - Definição das cores Fonte: Os Autores

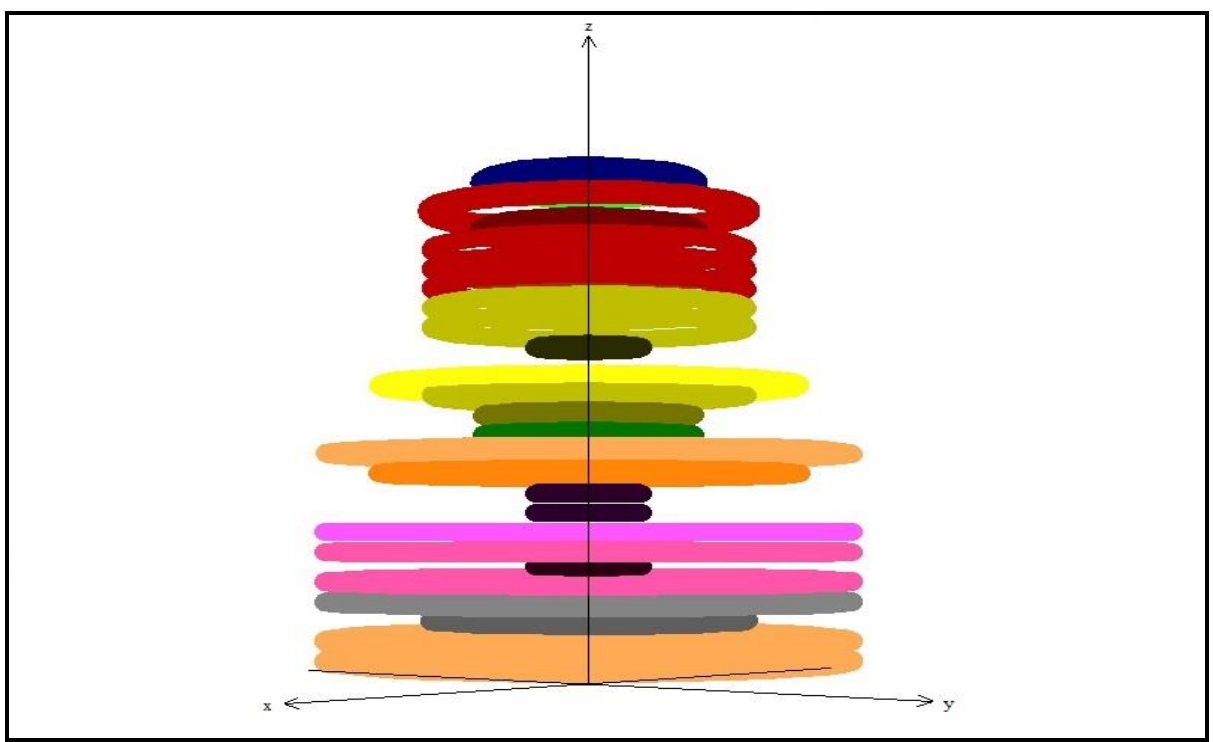

FIGURA 2 - Imagem-síntese do OA 1, Apostila de instrumentalização para o ensino à distância Fonte: Os Autores

Os discos de diâmetro mais estreito representam valores menores (1 ou aproximados) conforme a intensidade de 1 a 5 definida na tabela de variáveis. O tom azul-escuro representa intensidade 3 na categoria da Teoria da Carga Cognitiva de Sweller (2003), o que remete a uma média na avaliação da aprendizagem de acordo com o alinhamento do processo de informação, demonstrando que, para este OA, a razão aprendizagem/informação é mediana. No que se refere ao Ciclo de Aprendizagem Vivencial de Kolb (1986), as intensidades 
variaram entre 2 e 4 , sendo que prevaleceu o valor 2, representado na maioria dos discos, em tom vermelho-claro, indicando baixa circularidade entre as categorias do ciclo de aprendizagem proposto pelo autor.

Já nas variáveis analisadas a partir dos Princípios de Mayer (2001), a intensidade alta gerou tons escuros de amarelo, com apenas uma variável em amarelo-claro, indicando que o objeto atende à classificação de qualidade nos princípios de design instrucional propostos conforme este modelo. O mesmo ocorreu com a categoria de Aprendizagem Significativa de Ausubel (1968), que avalia o OA quanto à integração do tema com as áreas de conhecimento, se existe relação com o conhecimento do aluno, a qual resultou em um tom verde mais escuro.

Quanto às categorias do padrão LOM de metadados, seus diâmetros ficaram mais largos, vistos que representam números maiores, indicando que o OA pode ser facilmente localizável e reutilizável dentro de vários contextos educacionais. As categorias podem ser identificadas nas legendas da Figura 3:

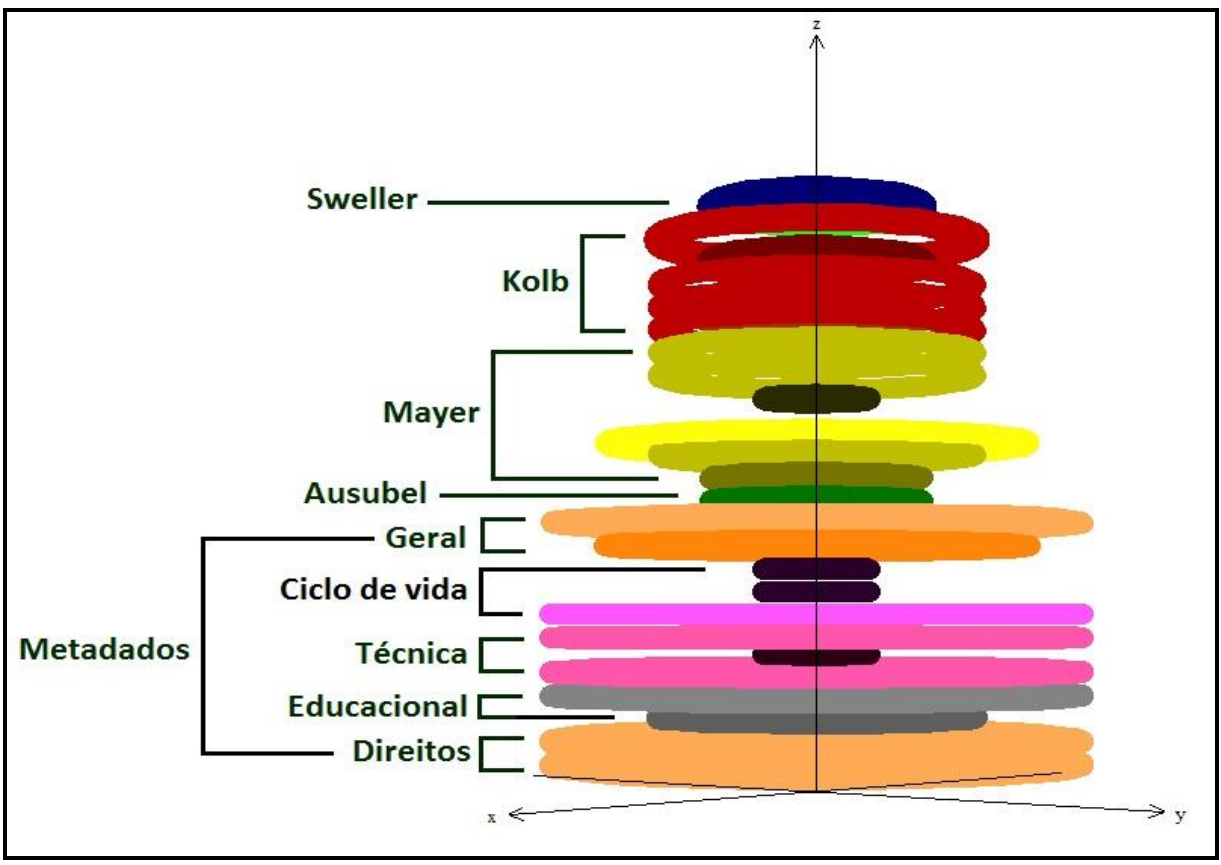

FIGURA 3 - Imagem-síntese do OA 1, com legenda Fonte: Os Autores

No que concerne ao OA2, o vídeo intitulado Motivação: existe mesmo um modo de ensiná-la aos alunos? os resultados do sólido revelam um OA cujas características analisadas pressupõe maior interação e didatismo na apresentação do objeto de conhecimento, embora ofereça menores possibilidades de acesso ao OA em sistemas operacionais e tecnologias diferentes, ainda que ambos OAs apresentem ciclos de vida parecidos em seus metadados.

O OA2 apresentou grande ocorrência nas categorias propostas para as teorias da aprendizagem, o que pode ser percebido pela largura do diâmetro na parte superior do objeto, 
embora as intensidades tenham sido avaliadas como mais leves, conforme pode-se perceber pelos tons de coloração clara.

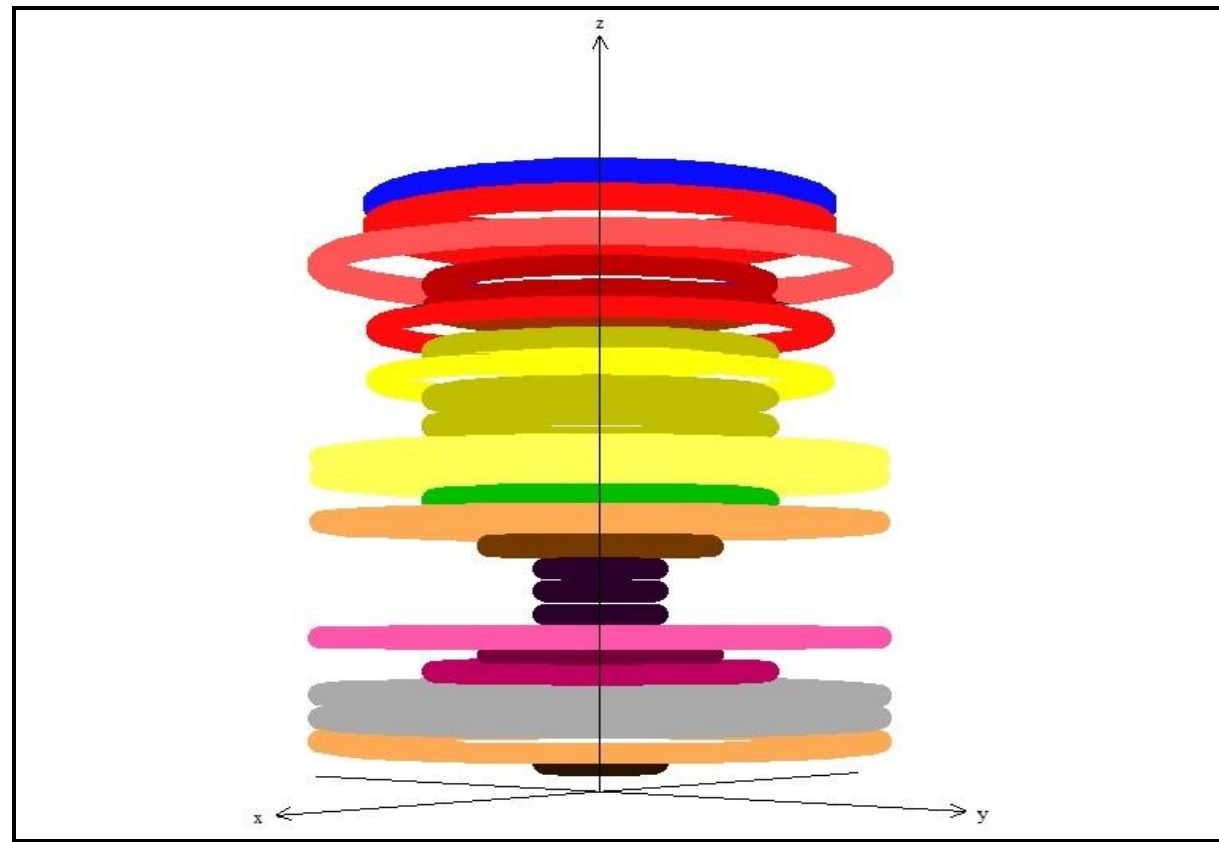

FIGURA 4 - Imagem-síntese do OA2, vídeo Motivação: existe mesmo um modo de ensiná-la aos alunos?

Fonte: Os Autores

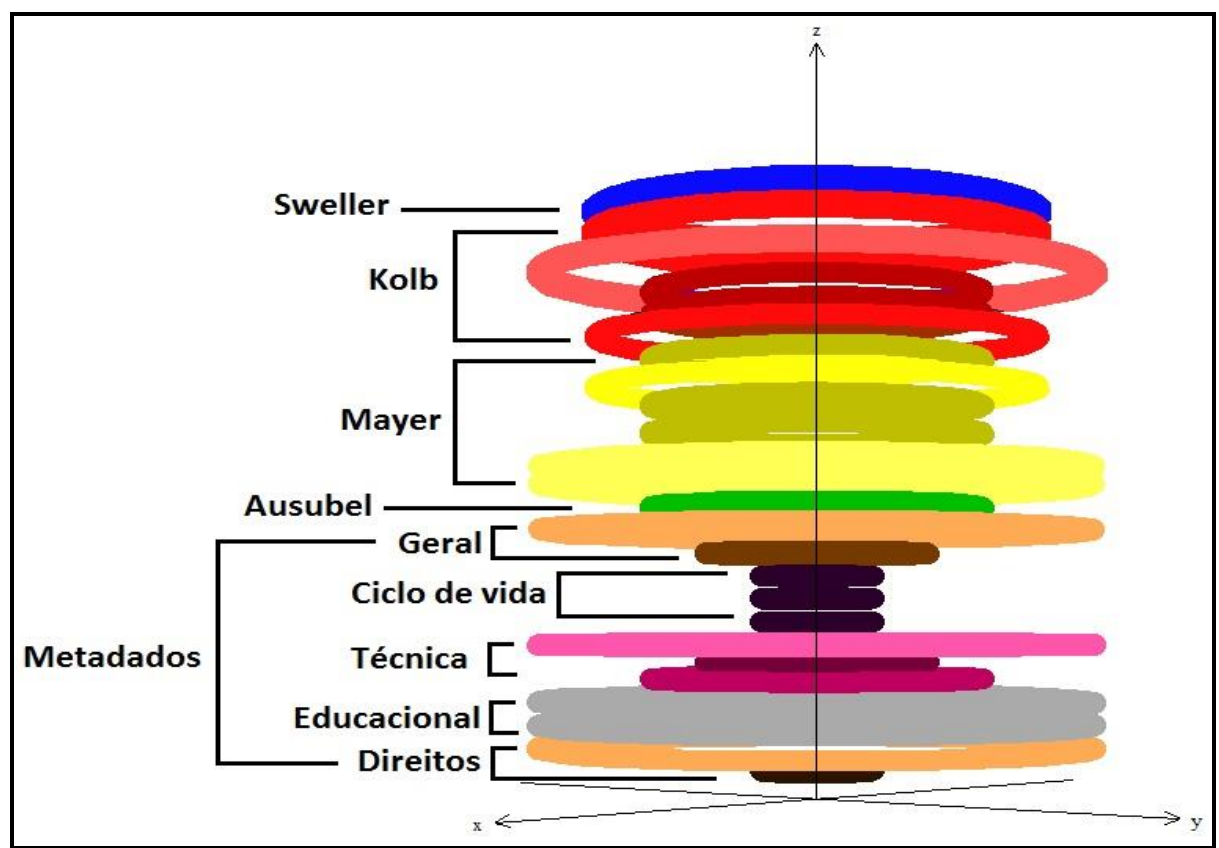

FIGURA 5 - Imagem-síntese do OA 2, com legenda

Fonte: Os Autores 


\section{CONSIDERAÇÕES FINAIS}

A pesquisa desenvolvida revelou profícua a possibilidade da inclusão da subjetividade na avaliação de OAs em dados, mediante a proposição de categorizações que levem em conta variáveis e intensidade na análise de OAs a partir de teorias de aprendizagem e de características padronizadas utilizadas em sua organização e catalogação em repositórios digitais. A fim de que a metodologia proposta fosse utilizada em sistemas de recomendação, seria necessário o desenvolvimento de pesquisa de larga escala, a fim de gerar dados e padrões para a consolidação da proposta.

Como afirma Manovich (2010), é possível utilizar outras categorias que superam a catalogação em caixas de valores fixos, puramente numéricos ou em ordem alfabética. A criação de tags de valor estético, mais do que contemplando uma função meramente organizacional, pode constituir-se como uma tendência na ordem contemporânea, em que as formas simbólicas implodem a linearidade e as lógicas unidirecionais e logocêntricas. A tendência à complexidade e às informações em rede demonstram seu potencial na sintetização imagética, muito embora necessitem de procedimentos aperfeiçoados de formas de conhecimento advindas da modernidade.

\section{REFERÊNCIAS}

AUSUBEL, Davi. Paul. Educational Psychology: A Cognitive View. New York, Holt, Rinehart and Winston, 1968.

BEHAR, Patricia. Alessandra. Modelos Pedagógicos em Educação a Distância. Porto Alegre: Artmed, 2009.

CAZELLA, Sérgio; REATEGUI, Eliseu; MACHADO, Munique; BARBOSA, Jorge. Recomendação de objetos de aprendizagem empregando filtragem colaborativa e competências. In: XX Simpósio Brasileiro de Informática na Educação (SBIE). Florianópolis. Anais do SBIE 2009. Disponível em: <http://www.brie.org/pub/index.php/sbie/article/view/1158/1061>. Acesso em: 20 jul. 2013.

CAZELLA, Sérgio; DRUMM, Jonas; BARBOSA, Jorge. Um serviço para recomendação de artigos científicos baseado em filtragem de conteúdo aplicado a dispositivos móveis. RENOTE - Revista Novas Tecnologias na Educação, v. 8, p. 22, 2010. Disponível em: <http://seer.ufrgs.br/index.php/renote/article/view/18057/10645>. Acesso em: 22 jul. 2013.

FLUSSER, Vilém. O mundo codificado: por uma filosofia do design e da comunicação. São Paulo: Cosac Naify, 2007.

HAUGHEY, Margaret; MUIRHEAD, Bill. Evaluating learning objects for schools. Journal of Instructional Science and Technology. v.8, n.1, 2005. Disponível em: $<$ http://www.usq.edu.au/electpub/eist/docs/vol8_no1/fullpapers/eval_learnobjects_school.ht m>. Acesso em: 16 abr. 2011. 
IEEE Learning Technology Standards Committee (LTSC). Draft Standard for Learning Object Metadata, Institute of Electrical and Electronics Engineers, Inc, 2000.

KOLB, David; RUBLIN, Irwin; MCINTYRE, James. Psicologia Organizacional: uma abordagem vivencial. São Paulo: Ed. Atlas, 1986.

LTSC. Learning technology standards committee. Website. 2000. Disponível em: <http://ltsc.ieee.org/>. Acesso em: 20 jul. 2012.

MANOVICH, Lev. Database. In: MANOVICH, L. The Language of The New Media. Cambridge, MA: MIT Press, 2001.

MANOVICH, Lev. Teoria dos Nurbs. In: PERISSINOTTO, Paula; BARRETO, Ricardo. Teoria Digital. Tradução de Cicero Inacio da Silva e Jane de Almeida. São Paulo: Imprensa Oficial, 2010, pgs. 108 a 133. Disponível em: <http://lab.softwarestudies.com/2011/11/teoriados-nurbs.html>. Acesso em: 3 abr. 2013.

MAYER, Richard. Multimedia Learning. Cambridge: Cambridge University Press, 2001.

MEYER, Marek. Modularization and Multi-Granularity Reuse of Learning Resources. 2008. pp 19-23. Disponível em: <http://tuprints.ulb.tu-darmstadt.de/ 1156/1 /Marek_Meyer_genehmigte_Dissertation.pdf>. Acesso em: 31 mar. 2011.

SANTAELLA, Lucia; NÖTH, Winfred. Imagem Cognição, Semiótica, Mídia. São Paulo: Iluminuras, $3^{\mathrm{a}}$ ed. 2001.

SANTAELLA, Lucia. Por que as comunicações e as artes estão convergindo? São Paulo: Paulus, 2005.

SILVA, Edna; CAFÉ, Lígia; CATAPAN, Araci. H. Os objetos educacionais, os metadados e os repositórios na sociedade da informação. Ciência da Informação. Brasília, DF, v. 39, n. 3, p. 93-104, set./dez., 2010.

SWELLER, John. Cognitive Load Theory: A Special Issue of educational Psychologist. LEA, Inc, 2003.

WEINBERGER, David. A nova desordem digital. Rio de janeiro: Elsevier, 2007.

WILEY, David A. Connecting learning objects to instructional design theory: a definition, a metaphor, and a taxonomy. 2000. Disponível em: <http://reusability.org/read/> . Acesso em: 28 abr. 2013.

WILEY, David A. Learning object design and sequencing theory. Doctoral dissertation, Brigham Young University, 2000. 
Como citar este documento:

GOMES, Raquel Salcedo et al. Visualização sintético-imagética de parâmetros e metadados de objetos de aprendizagem. Revista Digital de Biblioteconomia e Ciência da Informação, Campinas, SP, v. 13, n. 3, p. 632-652, set. 2015. ISSN 1678-765X. Disponível em: <http://periodicos.sbu.unicamp. br/ojs/index.php/rdbci/article/view/2107>. Acesso em: 18 Set. 2015. 